\title{
O ensino de ciências e a formação continuada de professores alfabetizadores: reconhecendo o campo de pesquisa
}

\section{RESUMO}

Emerson Nunes da Costa Gonçalves e193196@dac.unicamp.br https://orcid.org/0000-0001-8026-9277 Universidade Estadual de Campinas (Unicamp), Campinas, São Paulo (SP), Brasil

Mauricio Compiani compiani@unicamp.br https://orcid.org/0000-0002-9253-7571 Universidade Estadual de Campinas (Unicamp), Campinas, São Paulo (SP), Brasil

Carlos Alberto de Oliveira Magalhães Júnior

juniormagalhaes@hotmail.com https://orcid.org/0000-0002-1116-0777 Universidade Estadual de Maringá (UEM), Maringá, Paraná (PR), Brasil

\begin{abstract}
O ensino de Ciências nos anos iniciais da Educação Básica apresenta campo de pesquisa importante no que tange à alfabetização científica para crianças nesse segmento do ensino. Primeiro, pela curiosidade típica da faixa etária, e, depois, pela necessidade da construção de perfis de cidadãos reflexivos e críticos dos seus contextos vividos. Porém, pelas exigências quanto à apropriação da leitura e da escrita, dentre outros fatores, pouco se dá a devida atenção à construção de conhecimentos sobre ciência, principalmente, nos três primeiros anos do Ensino Fundamental (EF), período de transição entre a Educação Infantil e o EF. Na perspectiva de valorização do ensino de Ciências durante a alfabetização, este trabalho objetivou identificar e analisar pesquisas, teses e dissertações, que discutem a educação continuada de professores alfabetizadores como mediadores do conhecimento científico no Ciclo de Alfabetização. Para o levantamento, foi utilizado o Catálogo de Teses e Dissertações da Coordenação de Aperfeiçoamento de Pessoal de Nível Superior (Capes), delimitado o período de 2007 a 2018. Foram recuperados 73 trabalhos, dos quais, 31 tratavam da formação continuada de professores dos anos iniciais, focada no ensino de Ciências, demonstrando aumento do número de pesquisas que apresentam esse interesse. Porém, desse total, foram identificadas apenas 03 dissertações de mestrado que se dedicaram à formação continuada de professores alfabetizadores, indicando a necessidade da realização de pesquisas que possam colaborar com novos direcionamentos da alfabetização científica mediada pelo professor que ensina a ler e escrever.
\end{abstract}

PALAVRAS-CHAVE: Ciclo básico de alfabetização; Alfabetização; Educação continuada; Educação científica. 


\section{INTRODUÇÃO}

A própria natureza curiosa, inerente à criança, torna o ensino de Ciências necessário para que, já na infância, seja desenvolvido nos alunos de todo o Ensino Fundamental (EF) o perfil reflexivo e crítico sobre as questões que os integram, bem como os seus espaços vividos e experimentados (VIEIRA; TENREIRO-VIEIRA; MARTINS, 2014).

Tratarmos de Ciências nos anos iniciais, na tentativa de possibilidades de um ensino melhor, exige entendermos os contextos de atuação docente, de forma que essa melhoria está associada à formação inicial dos professores (FRACALANZA; AMARAL; GOUVEIA, 1986).

Tipicamente, os docentes dos anos iniciais são provenientes de cursos de pedagogia, onde a carga horária para o desenvolvimento de conhecimentos da área das Ciências da Natureza, geralmente, é ofertada em apenas um semestre, por exemplo, em disciplinas como Didática do Ensino de Ciência, o que acaba por Ihes conferir uma condição de professores polivalentes ou generalistas (SILVA, 2009; MEGID NETO; ROCHA, 2010; MAGALHÃES JÚNIOR; TOMANIK, 2013; AUGUSTO; AMARAL, 2015).

Essa é uma constatação importante, pois, há uma grande preocupação dos professores dos anos iniciais com o processo de alfabetização, principalmente, nos três primeiros anos do EF, tornando o ensino de Ciências um apêndice sem relevância, desenvolvido por obrigatoriedade do currículo prescrito (CHASSOT, 2014).

Porém, alfabetizar é promover aos alunos a capacidade de interpretar sua relação com o mundo, identificando-se nos espaços onde se movimentam, não sendo reduzido a um processo mecânico e rígido de manipulação de letras e palavras (FREIRE, 1990).

Nesse aspecto, o processo da alfabetização, a apropriação da leitura e da escrita, não deve estar dissociada da alfabetização científica, justificando que essa última "[...] deve ser desenvolvida desde o início do processo escolar, mesmo antes que a criança saiba ler e escrever" (LORENZETTI; DELIZOICOV, 2001, p. 13), sendo que, mesmo antes desse domínio, as crianças já são leitores do mundo, percebendo-o, sentindo-o, interagindo com seus contextos (FREIRE, 1989; FREIRE, 1990).

Lorenzetti e Delizoicov (2001) nos chamam atenção de que a partir do ensino de Ciências, o processo de alfabetização da criança pode ser potencializado pela construção de sentidos e significados na elaboração dos discursos na leitura e na escrita.

Pelo exposto, trazemos a questão do professor alfabetizador nos anos iniciais, mediador do conhecimento científico no Ciclo de Alfabetização, na tentativa de identificar o campo de estudo que trata da sua formação continuada, focado no ensino de Ciências.

Assim, o presente trabalho teve por objetivo identificar e analisar pesquisas que discutem a educação continuada de professores alfabetizadores como mediadores do conhecimento científico nos três primeiros anos da Educação Básica, a partir da seguinte questão: Qual é o atual cenário das investigações sobre 
a formação continuada de professores alfabetizadores, teses e dissertações, focadas no ensino de Ciências no Ciclo de Alfabetização?

Os resultados apresentados são parte integrante de uma pesquisa maior, aprovada pelo Conselho de Ética da Universidade Estadual de Capinas (Unicamp), Campinas-SP, no dia 01 de abril de 2018, sob C.A.A.E n. 79826017.8.0000.5404.

\section{ALFABETIZAÇÃO E ENSINO DE CIÊNCIAS}

Na história da educação, o processo de apropriação da escrita e da leitura, da introdução do ser humano no mundo das letras, a alfabetização, tornou-se objeto de manobras políticas de inserção do Homem no mundo como cidadão, instituindo o seu direito de ler e escrever, definindo sua capacidade de tomadas de decisões, principalmente, como consumidor ativo do tempo moderno, capitalista (SAVIANI, 2008).

Assim, ser analfabeto é estar à margem da sociedade, ou seja, vivenciar a marginalidade (SAVIANI, 2008; MARCÍLIO, 2016) e que "[...] alfabetizar o indivíduo na idade certa é fazer dele um membro de pleno direito da coisa pública, um cidadão em plenitude" (MARCÍLIO, 2016, p. 15), pois

$\mathrm{O}$ analfabetismo não só ameaça à ordem econômica de uma sociedade, como também constitui profunda injustiça. Essa injustiça tem graves consequências, como a incapacidade dos analfabetos de tomarem decisões por si mesmos, ou de participarem do processo político. Desse modo, o analfabetismo ameaça o caráter mesmo da democracia. Solapa os princípios democráticos de uma sociedade (FREIRE, 1990, p. XI).

A alfabetização brasileira é um processo que preocupa, desde sempre, governos, organizações não governamentais, gestores escolares, professores, pais e responsáveis, cada qual de acordo com suas necessidades e interesses, principalmente, a partir dos índices nacionais da educação pública obtidos com as provas externas realizadas pelo Instituto Nacional de Estudos e Pesquisas Educacionais Anísio Teixeira (INEP) (ALAVARSE; BRAVO; MACHADO, 2013; KUSIAK, 2012; BONAMINIO; SOUZA, 2012).

Segundo Marcílio (2016), entre os anos de 2001 a 2007, 75\% da população brasileira era composta por analfabetos funcionais, sendo que no ano de 2009, essa taxa baixou para $68 \%$ da população entre 15 e 64 anos, de forma que "[...] apenas 1 entre cada 4 brasileiros conseguia ler e escrever plenamente e utilizar essas habilidades para desenvolver sua vida" (MARCÍlIO, 2016, p. 15).

Os dados mais recentes, disponibilizados pelo Instituto Brasileiro de Geografia e Estatística (IBGE), em junho de 2019 (IBGE, 2019), apontam que 11,3 milhões de brasileiros são analfabetos, correspondendo a uma margem de $6,8 \%$ de analfabetismo de pessoas acima dos 15 anos, sendo que desse grupo $7 \%$ são homens e $6,6 \%$, mulheres, dados que se tornam mais preocupantes, quando identifica-se que, em qualquer grupo etário estudado, negros e pardos apresentam maior índice de analfabetismo, reforçando a necessidade de olhares sensíveis para essa desigualdade.

Algumas medidas políticas se destacam nesse âmbito da educação, focados na questão da apropriação do "[...] funcionamento do Sistema de Leitura 
Alfabética [...]" (LEAL, 2017, p. 95) e da "[...] alfabetização matemática” (FONSECA, 2017 , p. 170) na tentativa de elevar a qualidade do processo ensino-aprendizagem, desde a década de 1990, a partir dos índices produzidos pelo Sistema Nacional de Avaliação da Educação Básica (Saeb), que avaliou a cada dois anos, os alunos matriculados no 5ㅇ e 9o ano do Ensino Fundamental, e no 3ㅇ ano do Ensino Médio das escolas brasileiras (BONAMINIO; SOUZA, 2012).

Dessas iniciativas, dentre outras, sinalizamos a aprovação do EF de nove anos, a partir da Lei n. 11.274/2006, que incluiu, formalmente, a criança de seis anos no processo de alfabetização (BRASIL, 2006); a Provinha Brasil, instituída pela Portaria n. 10, de 24 de abril de 2007, que é uma avaliação diagnóstica, investigativa das habilidades desenvolvidas pelas crianças matriculadas no 2 을 ano do EF (BRASIL, 2007); e o Pacto Nacional pela Alfabetização na Idade Certa (PNAIC), instituído pela Portaria n. 867, de 4 de julho de 2012, com a proposta de assegurar que todas as crianças estejam alfabetizadas até os oito anos de idade, ao final do 3 ano do EF (BRASIL, 2012).

Porém, vale ressaltar que cabe aos professores alfabetizadores, para além da leitura e da escrita, também, promoverem aos seus alunos, nos anos iniciais, "[...] a compreensão do ambiente natural e social, do sistema político, da tecnologia, das artes e dos valores em que se fundamenta a sociedade" (BRASIL, 1996). Assim, nos identificamos com Leal $(2017$, p. 95) na sua forma de assumir a alfabetização:

\footnotetext{
[...] como um processo em que ao mesmo tempo, as crianças possam aprender como é o funcionamento do Sistema de Escrita Alfabética, de modo articulado e simultâneo às aprendizagens relativas aos usos sociais da escrita e da oralidade [...] como um processo em que as crianças aprendem a ler, a escrever, a falar, a escutar, mas se apropriam, por meio da leitura, da escrita, da fala, da escuta, de conhecimentos relevantes para a vida.
}

Considerarmos o processo de alfabetização escolar, valorizando a importância social da ação da escrita e da leitura, baseado em práticas que contextualizem as questões reais do aluno, é, também, um convite a um olhar diferenciado para a sua alfabetização científica, pois desde a educação infantil já são sensíveis aos fenômenos naturais, de forma que

\footnotetext{
Apoiar as crianças à medida que desenvolvem o pensamento científico durante os primeiros anos da infância pode levá-las a transferirem facilmente suas habilidades de pensamento para outros domínios acadêmicos que favoreçam seu desempenho escolar e sua autonomia (TRUDLE, 2009, p. 01 tradução nossa).
}

A valorização do ensino sobre ciências durante a sua alfabetização é relevante uma vez que devemos entender as crianças, nessa etapa do seu desenvolvimento, como seres ativos e capazes de interatividade com os fenômenos naturais que os cercam, uma característica potencializadora da capacidade de aprendizado (TRUNDLE, 2010; SAÇKES; FLEVARES; TRUNDLE, 2010), além da obrigação legal da oferta da disciplina Ciências, pelas escolas (BRASIL, 1996).

Mas, há uma pressão social e política sobre as escolas, sobre os professores e consequentemente moral e ética sobre as crianças, ao serem inseridas nos primeiros anos do EF. As crianças são condicionadas à compartimentação do tempo, dos pensamentos e da construção do conhecimento, como se aprender fosse, cronometradamente, um momento inerte aos fenômenos experienciados 
por elas, desconsiderando suas vivências prévias, suas construções sócio-históricas (GOULART, 2017).

Atualmente, com a recente implantação da Base Nacional Curricular Comum (BNCC), muitas são as discussões sobre as mudanças impostas sobre as escolas e professores, dentre elas, o fim do ciclo de três anos para alfabetização das crianças, reduzindo-se esse tempo para o $2^{\circ}$ ano ao invés do 3 ㅇ; a readequação curricular, verticalmente imposta pelo MEC; e a reformulação das demandas para as avaliações externas, que a partir do ano de 2019 passam a vigorar em creches, préescola, além do 2 o ano do EF (INEP, 2019).

\section{EDUCAÇÃO CONTINUADA DE PROFESSORES ALFABETIZADORES DOS ANOS INICIAIS}

A formação continuada dos professores dos anos iniciais do EF, vai muito além do que é, simplesmente, imaginarmos quais caminhos seriam viáveis para Ihes proporcionar momentos de ensino-aprendizagem que os supram nos aspectos de uma suposta defasagem tecnocientífica, em relação, por exemplo, aos conteúdos das Ciências da Natureza, cuja formação inicial, nos cursos de pedagogia, não lhes tenham possibilitado maior acesso.

Para Nóvoa (1995), a formação continuada deve valorizar as experiências inovadoras e a coletividade dos sistemas educacionais, focado em propostas qualitativas da ação docente e da sua progressão profissional, sem perspectivas a instauração de instrumentos de controle, mas de práticas inovadoras definidas nos saberes construídos na própria escola.

O planejamento de propostas de formação continuada para professores alfabetizadores exige de nós, pesquisadores e formadores, enquanto instituições mantenedoras e formativas, entendermos o universo ao qual estão submetidos os dois principais atores do processo de aprender a ler e escrever, a criança e o professor (MORORÓ; BASSO, 2005; LEITE, 2010). Isso nos leva aos seguintes questionamentos: o quanto suas histórias, e como essas se constituem, são material único para descoberta de caminhos cada vez melhores para o processo de ensino-aprendizagem da leitura e da escrita em salas de aulas, cada vez mais, múltiplas de diversidade social, cultural, política e econômica? Como o ensino de Ciências é integrador de possibilidades para uma educação transformadora desde os primeiros anos da infância?

Pesquisadores como Megid Neto e Rocha (2010), e Lima, Bello e Siqueira (2015), apresentam dados que destacam a necessidade do surgimento de pesquisas que tenham por interesse a formação inicial e continuada dos professores que ensinam Ciências nos anos iniciais.

Megid Neto e Rocha (2010) realizaram um levantamento bibliográfico, entre 2003 e 2008, com o objetivo de identificarem trabalhos com propostas alternativas para a formação inicial e continuada de professores de Ciências nos anos iniciais, a partir de cinco periódicos brasileiros e quatro internacionais, respectivamente, citados: 
Journal of Science Teacher Education; Research in Science Education; Journal of Elementary Science Education; International Journal of Science Education (MEGID NETO; ROCHA, 2010, p. 156).

Os autores identificaram nove artigos relacionados aos estudos de práticas de formação inicial e continuada, sendo que destes, quatro tratavam somente da formação inicial (TRUNDLE; ATWOOD; CHRISTOPHER, 2006; ZIMMERMANN; EVANGELISTA, 2007; LOGHINI, 2008; NILSSON, 2008); um fazia uma análise tanto da formação inicial como da continuada (LOGHINI; HARTWING, 2007); e quatro, exclusivamente, da formação continuada de professores dos anos iniciais (MONTEIRO; TEIXERIA, 2004; JARVIS; PELL, 2004; AKERSON, 2005; DIXON; WILKE, 2007).

Lima, Bello e Siqueira (2015) analisaram artigos de seis periódicos que abordam o ensino de Ciências publicados entre os anos de 2004 a 2013 (Tabela 1): Revista Ciência \& Educação (C \& E): volume 15 (2004) ao volume 19 (2013); Revista Investigação em Ensino de ciências (IENCI): volume 14 (2004) ao volume 18 (2013); Revista Brasileira de Pesquisa em Educação em Ciências (RBPEC): volume 9 (2004) ao volume 13 (2013); Revista Experiências em Ensino de Ciências (EENCI): volume 4 (2004) ao volume 8 (2013); Revista Electrónica de Enseñanza de las Ciencias (REEC): volume 7 (2004) ao volume 12 (2013); Revista de Educação, Ciência e Tecnologia (Alexandria): volume 2 (2004) ao volume 7 (2013).

Tabela 1 - Demonstrativo da produção científica das revistas analisadas entre os anos de 2004 e 2013 por Lima, Bello e Siqueira (2015)

\begin{tabular}{|c|c|c|c|c|c|c|c|c|c|c|c|}
\hline Período/Revista & $\mathbf{2 0 0 4}$ & $\mathbf{2 0 0 5}$ & $\mathbf{2 0 0 6}$ & $\mathbf{2 0 0 7}$ & $\mathbf{2 0 0 8}$ & $\mathbf{2 0 0 9}$ & $\mathbf{2 0 1 0}$ & $\mathbf{2 0 1 1}$ & $\mathbf{2 0 1 2}$ & $\mathbf{2 0 1 3}$ & Total \\
\hline C \& E & 40 & 36 & 24 & 28 & 36 & 39 & 45 & 60 & 60 & 60 & 428 \\
EENCI & - & - & 18 & 18 & 18 & 24 & 36 & 36 & 21 & 32 & 203 \\
IENCI & 13 & 17 & 18 & 18 & 18 & 20 & 24 & 24 & 36 & 35 & 223 \\
REEC & 23 & 21 & 22 & 30 & 40 & 58 & 96 & 29 & 33 & 27 & 379 \\
RBPEC & 24 & 15 & 12 & 12 & 18 & 20 & 22 & 30 & 30 & 29 & 212 \\
Alexandria & - & - & - & - & 18 & 22 & 14 & 21 & 30 & 33 & 138 \\
\hline Total & 100 & 89 & 94 & 106 & 148 & 183 & 237 & 200 & 210 & 216 & 1583 \\
\hline \multicolumn{7}{|c}{ Fonte: Adaptado de Lima, Bello e Siqueira (2015). } \\
\hline
\end{tabular}

Esses autores constataram que, do total de 1583 artigos analisados, em apenas onze os professores dos anos iniciais eram público alvo de interesse, caracterizando a necessidade de investigações que foquem na formação continuada desses docentes quanto ao ensino de Ciências.

Mesmo que a análise, por vezes, abranja questões menos específicas, identifica-se poucos trabalhos que se dedicam à alfabetização científica nos anos iniciais, a exemplo da pesquisa de Fernandes (2015) que, produzindo uma discussão sobre dissertações e teses brasileiras que investigaram sobre as práticas pedagógicas nesse segmento do ensino, de um total de cinco mil trabalhos, apenas oitenta e sete foram desenvolvidas entre as anos de 1972 e 2012; e de Viecheneski, Lorenzetti e Carletto (2015), que da análise realizada sobre os trabalhos apresentados no Encontro Nacional de Pesquisa em Educação em Ciências (ENPEC), entre os anos de 1997 a 2013, em nove edições do evento, somente vinte e cinco contemplavam discussões sobre o ensino de Ciências nos anos iniciais. 
A partir dos indicativos citados; das peculiaridades que envolvem o ensino de Ciências nos anos iniciais; e da importância da construção de novas concepções sobre o processo de alfabetização na infância e sua relação com o ensino de Ciências, percebeu-se a necessidade de se entender como estão situadas, em âmbito nacional, as pesquisas acadêmicas que tratam da formação continuada dos professores alfabetizadores quanto ao ensino de Ciências no Ciclo de Alfabetização, utilizando como campo de pesquisa o Catálogo de Teses e Dissertações da Capes.

\section{METODOLOGIA}

O Catálogo de Teses e Dissertações da Capes é uma plataforma de pesquisa bibliográfica e possui o acervo das teses e dissertações de pesquisas realizadas em programa de doutorado e mestrados reconhecidos, com arquivos dos textos completos, enviados pelos programas de pós-graduação a partir de 2010, e metadados de pesquisas realizadas antes desse período (CAPES - BOLETIM n. 37, 2018).

Os meios eletrônicos de busca em plataformas online estão tecnologicamente mais avançados, proporcionando a obtenção de resultados com agilidade e condição de refinamento sobre o objeto de pesquisa. Porém, é necessário o planejamento que direcione adequadamente o rastreamento dos dados tal que

A metodologia deve conter um conjunto de ações ou táticas relacionadas com restrições e/ou limites determinados pelo usuário. $O$ pesquisador também deve traduzir sua necessidade utilizando, além da estratégia, algumas outras especificações, como, por exemplo, o uso de palavras-chave bem direcionadas (PORTAL CAPES, BOLETIM N. 52, 2018).

Nas pesquisas realizada no Catálogo de Teses e Dissertações da Capes, a definição das palavras-chave pode ser enriquecida por operadores booleanos: aspas (" "), na busca de frases exatas ou ordem na qual os termos podem aparecer, resultando em quantidade apurada dos documentos recuperados; AND, que possibilita combinações dos termos que traduzem o interesse do pesquisador; OR, que seleciona documentos com no mínimo, um dos termos; e NOT, que "[...] exclui termos para que cada resultado não contenha nenhum dos termos que o seguem" (CAPES - BOLETIM N. 52, 2018) (Figura 1). 
Figura 1 - Representação da utilização dos operadores booleanos como auxiliares no processo de refinamento de levantamentos de dados.

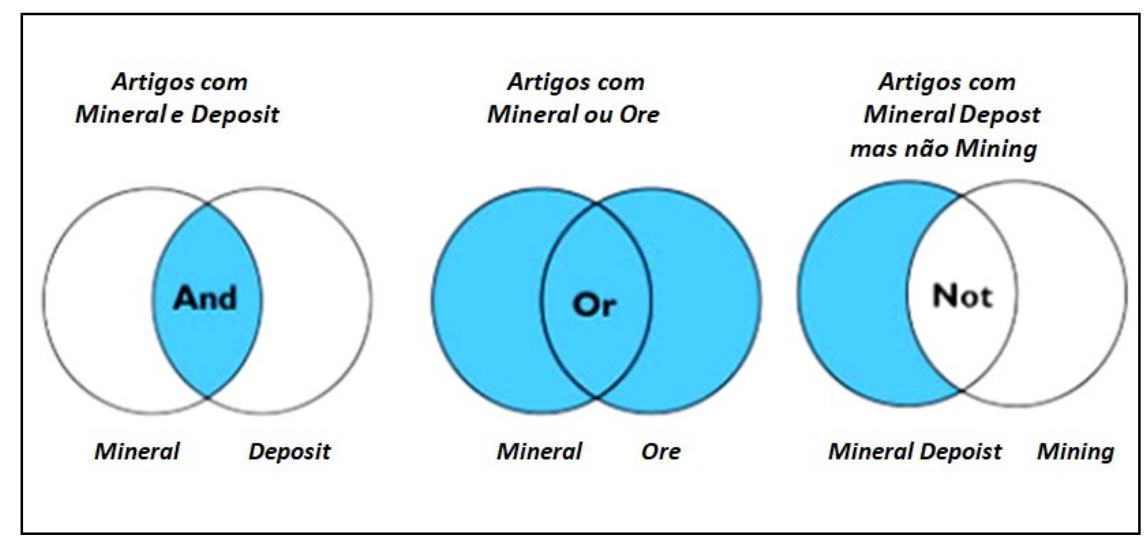

Fonte: Boletim Eletrônico Portal de Periódicos da CAPES, N. 52 (2018).

George Boole, um matemático e filósofo britânico (1815-1864), foi quem desenvolveu essa metodologia, a partir de três operações básicas (and, or e not), sendo "[...] utilizada no processamento de dados de computador, na automatização da produção industrial, na teoria aplicada aos fluídos e na ciência da informação" (CAPES - BOLETIM N. 52, 2018).

Dessa forma, para o território de levantamento sugerido, o Catálogo de Teses e Dissertações da Capes, foram definidos os descritores formação de professores, anos iniciais e ensino de Ciências, com utilização dos booleanos aspas (" ") e and, de acordo a proposta: "formação continuada de professores" and "anos iniciais" and "ensino de ciências".

Para definição desses descritores, levou-se em consideração o interesse da pesquisa pela etapa de ensino correspondente ao Ciclo de alfabetização legalmente definido em 2006, o que nos permite dar ênfase ao termo "anos iniciais" para caracterização do período entre os anos de 2007 e 2018 como a nomenclatura mais atual, em detrimento a outros mais antigos como "primário" ou "primeiro segmento", culminando com possíveis trabalhos voltados para a formação de professores alfabetizadores, bem como a implementação do PNAIC, a partir do ano de 2012.

De acordo com o objetivo dessa investigação, foram selecionadas as teses e dissertações que tratam da formação continuada de professores dos anos iniciais para o ensino de Ciências, e organizadas de acordo com: o seu título; o ano da sua publicação; o tipo de pesquisa; o ano da defesa; o programa de acordo com especificação da Capes; o autor; o orientador; e a instituição de origem. Para a seleção foram levados em consideração os descritores presentes no título da pesquisa, a leitura dos resumos e, quando necessário, a consulta à pesquisa no repositório de destino, sendo classificados de acordo com um código "T.x" e "D.y", onde " $T$ " corresponde à tese de doutorado, " $D$ " à dissertação de mestrado, e " $x$ " e "y" à sua identificação específica (T.1; T.2... T.9; D.1; D.2... D.21). 


\section{RESULTADOS E DISCUSSÃO}

No que tange ao último levantamento realizado no Banco de Teses e Dissertações da Capes, desde o mês de novembro de 2018, foram resgatados, em 03 de junho de 2019 (03/06/2019), o total de 79 registros, pesquisas produzidas no intervalo de tempo entre os anos de 2007 e 2018, estando distribuídas em: 15 teses de doutorado; 33 dissertações de mestrado acadêmico; 25 dissertações de mestrado profissional; e 06 trabalhos de nível profissionalizante. Para análise investigativa, desconsiderou-se os trabalhos profissionalizantes, perfazendo-se o total de 73 trabalhos, entre dissertações e teses.

Os dados coletados demonstraram que houve aumento no interesse dos pesquisadores que tratam da formação de professores, focados nos anos iniciais, desde 2007, para pesquisas de mestrado, e a partir de 2009, para pesquisa de doutorado, como apresentado no Quadro 1:

Quadro 1 - Quantitativo de dissertações e teses resgatadas

\begin{tabular}{|c|c|c|c|}
\hline \multirow{2}{*}{ Ano de defesa } & \multicolumn{2}{|c|}{ Tipo de Pesquisa } & \multirow{2}{*}{ Total } \\
\cline { 2 - 3 } & Mestrado & Doutorado & 01 \\
\hline 2007 & 01 & - & 02 \\
\hline 2008 & 02 & - & 01 \\
\hline 2009 & - & 01 & 01 \\
\hline 2010 & 01 & - & - \\
\hline 2011 & - & - & 03 \\
\hline 2012 & 02 & 01 & 01 \\
\hline 2013 & - & 02 & 07 \\
\hline 2014 & 05 & 03 & 12 \\
\hline 2015 & 09 & 02 & 13 \\
\hline 2016 & 11 & 02 & 13 \\
\hline 2017 & 17 & 03 & 73 \\
\hline 2018 & 10 & 15 & \\
\hline TOTAL & 58 & \multicolumn{3}{c}{} \\
\hline
\end{tabular}

Chamou atenção o intervalo de tempo entre os anos de 2014 e 2017 onde as investigações de mestrado apresentaram aumento considerável de interesse dos pesquisadores pelos anos iniciais, sendo que das 42 dissertações resgatadas nesse período, 03 delas se concentram na área de conhecimento "Educação"; 03 na área de conhecimento "Ensino"; e as outras 36 estão classificadas como pertencentes à área de conhecimento "Ensino de Ciências e Matemática", sendo que, desse total, 22 dissertações foram produzidas em programas de mestrados acadêmicos e 20 em programas de mestrados profissionais.

Esses números são acompanhados de maior incidências das pesquisas de doutorado entre os anos de 2014 e 2018, de forma que do total de 15 teses resgatadas, 12 estão concentradas nesse intervalo de tempo e classificados quanto a sua área de conhecimento da seguinte forma: 01 tese na área de Biofísica; 02 teses na área de Educação; 03 teses na área de Ensino; e 06 na área de Ensino de Ciências e Matemática.

Percebeu-se que a área de ensino de Ciências e Matemática tem se demonstrado com relevante contribuição para o campo da formação continuada 
de professores dos anos iniciais, um dado constatado por Nardi (2015, p. 07), que nos chama atenção de que há "[...] expressiva contribuição da pesquisa em Ensino de Ciências e Matemática para a educação no Brasil [...] com a criação da área (46) de Ensino de Ciências e Matemática da CAPES, em setembro de 2000".

Desatacou-se que das 73 produções acadêmicas resgatadas nesse levantamento, 09 teses se dedicaram ao ensino de Ciências, e 06 foram voltadas ao ensino de Matemática; enquanto, das 58 dissertações de mestrado, 22 tiveram seus objetivos focados no ensino de Ciências; 33 no ensino de Matemática; 01 em Ensino Religioso; 01 no ensino de Inglês; e 01 na Educação Ambiental. Pela investigação proposta, foram selecionadas, para análise, as teses e dissertações que tinha foco no ensino de Ciências, sendo organizadas nos Quadros 2 e 3.

Quadro 2: Teses de doutorado que tratam da formação continuada de professores dos anos iniciais, focadas no ensino de Ciências

\begin{tabular}{|c|c|}
\hline Código & I. Astronomia nos anos iniciais do ensino fundamental: repensando a formação de \\
\hline T.1 & $\begin{array}{l}\text { professores; II. 2009; III. Doutorado Acadêmico; IV. Educação Para a Ciência } \\
(33004056079 \text { p0); V. Rodolfo Langhi; VI. Roberto Nardi; VII. Unesp. }\end{array}$ \\
\hline T.2 & $\begin{array}{l}\text { I. Os desafios e as possibilidades de ensinar ciências nos anos iniciais do ensino fundamental: } \\
\text { uma investigação com professores; II. 2014; III. Doutorado Acadêmico; IV. Educação Para A } \\
\text { Ciência (33004056079p0); V. Fabricio Vieira de Moraes; VI. Renato Eugenio da Silva Diniz; } \\
\text { VII. Unesp - Bauru. }\end{array}$ \\
\hline T.3 & $\begin{array}{l}\text { I. O ensino de ciências nos anos iniciais do ensino fundamental e a formação continuada de } \\
\text { professores: implantação e avaliação do programa formativo de um centro de ciência; II. } \\
\text { 2014; III. Doutorado Acadêmico; IV. Ciências Biológicas (Biofísica) (31001017012p6); V. } \\
\text { Grazielle Rodrigues Pereira; VI. Robson Coutinho Silva; VII. UFRJ. }\end{array}$ \\
\hline T.4 & $\begin{array}{l}\text { I. As contribuições de um curso de formação continuada de professores que atuam nos anos } \\
\text { iniciais acerca das concepções epistemológicas e sua relação com a prática pedagógica; II. } \\
\text { 2015; III. Doutorado Acadêmico; IV. Educação Em Ciências Química da Vida E Saúde (Ufsm - } \\
\text { Furg) (42001013098p9); V. Viviane Maciel Machado Maurente; VI. Lisiane de Oliveira } \\
\text { Porciuncula; VII. UFSM - FURG. }\end{array}$ \\
\hline T.5 & $\begin{array}{l}\text { I. A construção coletiva de aulas para o ensino de ciências: uma proposta de formação } \\
\text { continuada com professoras dos anos iniciais do ensino fundamental; II. 2016; III. Doutorado } \\
\text { Acadêmico; IV. Educação Para a Ciência (33004056079p0); V. Aline Juliana Oja; VI. Fernando } \\
\text { Bastos; VII. Unesp; - Bauru. }\end{array}$ \\
\hline T.6 & $\begin{array}{l}\text { I. Formação continuada para o ensino de ciências na perspectiva ciência, tecnologia e } \\
\text { sociedade (cts): contribuições para professores dos anos iniciais; II. 2017; III. Doutorado } \\
\text { Acadêmico; IV. Ensino de Ciência e Tecnologia (40006018028p7); V. Fabiane Fabri; VI. } \\
\text { Rosemari Monteiro Castilho Foggiatto Silveira; VII. UTFPR. }\end{array}$ \\
\hline T.7 & $\begin{array}{l}\text { I. Formação continuada de professores em natureza da ciência e tecnologia com enfoque } \\
\text { nas competências científicas; II. 2017; III. Doutorado Acadêmico; IV. Ensino de Ciências } \\
\text { (33078017009p8); V. Sonia Aparecida Cabral; VI. Sonia Aparecida Cabral; VII. Univ. Cruzeiro } \\
\text { Do Sul. }\end{array}$ \\
\hline T.8 & $\begin{array}{l}\text { I. Um estudo sobre o desenvolvimento profissional de professores dos anos iniciais do } \\
\text { ensino fundamental, embasado na inserção de conteúdos de física no ensino de ciências e } \\
\text { na produção acadêmica da área, como elementos inovadores, sob a assessoria de uma } \\
\text { universidade; II. 2018; III. Doutorado Acadêmico; IV. Educação para a Ciência } \\
\text { (33004056079p0); V. Sorandra Correa de Lima; VI. Roberto Nardi; VII. Unesp - Bauru. }\end{array}$ \\
\hline T. 9 & $\begin{array}{l}\text { I. Formação continuada de professores dos anos iniciais do ensino fundamental: } \\
\text { contribuições para a reelaboração das práticas pedagógicas em ciências naturais; II. 2018; } \\
\text { III. Doutorado Acadêmico; IV. Educação (21001014001p6); V. Maria Oneide Lino da Silva; } \\
\text { VI. Jose Augusto de Carvalho Mendes Sobrinho; VII. UFPI. }\end{array}$ \\
\hline
\end{tabular}

Fonte: Autoria própria (2019) - Legenda: Trabalho (I); Ano de realização (II); Tipo de trabalho (III); Programa (IV); Autor (V); Orientador (VI); Instituição de origem (VII). 
Quadro 3: Dissertações de mestrado que tratam da formação continuada de professores dos anos iniciais, focadas no ensino de Ciências

\begin{tabular}{|c|c|}
\hline Código & \multirow{2}{*}{$\begin{array}{l}\text { I. Estudo etnográfico das contribuições da sociolinguística à introdução ao letramento } \\
\text { científico no início da escolarização; II. 2007; III. Mestrado Acadêmico; IV. Educação; V. } \\
\text { Salete Flores Castanheira; VI. Stell Maris Bortoni-Ricardo; VII. UnB. }\end{array}$} \\
\hline D.1 & \\
\hline D. 2 & $\begin{array}{l}\text { I. Formação continuada de professores de ciências para o ensino de astronomia nos anos } \\
\text { iniciais do ensino fundamental; II. 2012; III. Mestrado Acadêmico; IV. Educação; V. Rosimere } \\
\text { da Silva Dantas; VI. André Ferrer P. Martins; VII. UFRN. }\end{array}$ \\
\hline D.3 & $\begin{array}{l}\text { I. O uso do blog aliado ao ensino de ciências para a formação dos professores dos anos } \\
\text { iniciais do ensino fundamental; II. 2014; III. Mestrado Profissional; IV. Ensino de Ciência e } \\
\text { Tecnologia (40006018006p3); V. Caroline Elizabel Blaszko; VI. Marcia Regina Carletto; VII. } \\
\text { UTFPR. }\end{array}$ \\
\hline D.4 & $\begin{array}{l}\text { I. Ensino de ciências na perspectiva da alfabetização científica: prática pedagógica no ciclo } \\
\text { de alfabetização; II. 2015; III. Mestrado Acadêmico; IV. Educação (42003016014p2); V. Igor } \\
\text { Daniel Martins Pereira; VI. Marta Nornberg; VII. UFPel. }\end{array}$ \\
\hline D.5 & $\begin{array}{l}\text { I. Formação continuada de professores e a metodologia de ensino por investigação nos anos } \\
\text { iniciais do ensino fundamental de Paraúna-GO; II. 2015; III. Mestrado Profissional; IV. } \\
\text { Educação para Ciências e Matemática (52005011002p5); V. Marcelo Bueno Moura; VI. Paulo } \\
\text { Henrique de Souza; VII. IFG. }\end{array}$ \\
\hline D.6 & $\begin{array}{l}\text { I. Práticas de ensino por investigação nas aulas de ciências desenvolvidas nos anos iniciais } \\
\text { do ensino fundamental; II. 2015; III. Mestrado Profissional; IV. Formação Científica, } \\
\text { Educacional e Tecnológica (40006018019p8); V. Jose Augusto Real Limeira; VI. Arandi } \\
\text { Ginane Bezerra Junior; VII. UTFPR. }\end{array}$ \\
\hline D.7 & $\begin{array}{l}\text { I. Análise de uma proposta de ensino de ciências interdisciplinar na perspectiva histórico - } \\
\text { crítica com o uso da webquest; II. 2016; III. Mestrado Profissional; IV. Ensino de Ciências } \\
\text { Humanas, Sociais e da Natureza (40006018027p0); V. Giselle Palermo Schurch; VI. Zenaide } \\
\text { de Fatima Dante Correia Rocha; VII. UTFPR. }\end{array}$ \\
\hline D.8 & $\begin{array}{l}\text { I. Ensino de ciências nos anos iniciais do ensino fundamental: prática docente dos } \\
\text { professores da rede municipal de Uruaçu; II. 2016; III. Mestrado Profissional; IV. Ensino de } \\
\text { Ciências (52012018007p0); V. Orlandina Aparecida Borges Mendes; VI. Cleide Sandra } \\
\text { Tavares; VII. UEG. }\end{array}$ \\
\hline D.9 & $\begin{array}{l}\text { I. Formação continuada de professores do ensino fundamental: implicações para as práticas } \\
\text { pedagógicas em aulas de ciências nos anos iniciais; II. 2016; III. Mestrado Profissional; IV. } \\
\text { Ensino de Ciências e Matemática (11001011007p6); V. Dilair do Vale; VI. Aline Andreia } \\
\text { Nicolli; VII. UFAC. }\end{array}$ \\
\hline D.10 & $\begin{array}{l}\text { I. Uma proposta de formação continuada de professores: elaboração de sequência didática } \\
\text { com atividade experimental investigativa para o ensino de ciências nos anos iniciais; II. 2016; } \\
\text { III. Mestrado Profissional; IV. Ensino de Ciências (51001012022p8); V. Alessandra Ferreira } \\
\text { Beker Daher; VI. Vera de Mattos Machado; VII. UFMS. }\end{array}$ \\
\hline D.11 & $\begin{array}{l}\text { I. Tratamento interdisciplinar entre matemática e ciências nos livros didáticos de 4으 50 ano } \\
\text { do ensino fundamental campinas; II. 2016; III. Mestrado Acadêmico; IV. Educação } \\
\text { (33006016005p7); V. Diego da Silva Gallet; VI. Maria Auxiliadora Bueno Andrade Megid; VII. } \\
\text { PUC. } \\
\text { - Campinas }\end{array}$ \\
\hline D.12 & $\begin{array}{l}\text { I. Formação continuada de professores dos anos iniciais da educação básica: contribuições } \\
\text { de uma intervenção formativa em ciências naturais; II. 2016; III. Mestrado Acadêmico; IV. } \\
\text { Educação Científica e Formação de Professores (28006011010p6); V. Floraci Souza Caroso; } \\
\text { VI. Ana Cristina Santos Duarte; VII. UESB. }\end{array}$ \\
\hline D.13 & $\begin{array}{l}\text { I. Formação de professores de ciências dos anos iniciais: uma proposta de sequência didática } \\
\text { problematizadora com o conteúdo queimadas; II. 2017; III. Mestrado Profissional; IV. Ensino } \\
\text { de Ciências (51001012022p8); V. Catia Fabiane Reis Castro; V. Vera de Mattos Machado; VII. } \\
\text { UFMS. }\end{array}$ \\
\hline D.14 & $\begin{array}{l}\text { I. Formação continuada de professores sobre gestão de resíduos sólidos: uma proposta para } \\
\text { alfabetização científica nos anos iniciais; II. 2017; III. Metrado Profissional; IV. Ensino de } \\
\text { Ciências Naturais e Matemática (41006011010p3); V. Idione Da Silva; VI. Arleide Rosa da } \\
\text { Silva; VII. FURB. }\end{array}$ \\
\hline D.15 & $\begin{array}{l}\text { I. Práticas experimentais em física: uma abordagem para os anos iniciais do ensino } \\
\text { fundamental; II. 2017; III. Mestrado Profissional; IV. Ciências e Tecnologias na Educação } \\
\text { (42033012002p0); V. Carmem Regina Pereira da Silva Diehl; VI. Marcos Andre Betemps Vaz } \\
\text { da Silva; VII. IFSUL. }\end{array}$ \\
\hline
\end{tabular}


Quadro 3: (Cont.)

\begin{tabular}{|c|c|}
\hline D.16 & $\begin{array}{l}\text { I. Ensino de ciências por investigação: um desafio à formação dos professores dos anos } \\
\text { escolares iniciais; II. 2017; III. Mestrado Profissional; IV. Docência em Educação em Ciências } \\
\text { e Matemáticas (15001016078p1); V. Gilma Favacho Amoras Soares; VI. Terezinha Valim } \\
\text { Oliver Goncalves; VII. UFPA. }\end{array}$ \\
\hline D.17 & $\begin{array}{l}\text { I. Políticas de formação continuada aos professores dos anos iniciais de mato grosso para o } \\
\text { uso pedagógico das tecnologias digitais no ensino de ciências; II. 2017; III. Mestrado } \\
\text { Acadêmico; IV. Ensino De Ciências e Matemática (50002015101p9); V. Juciley Benedita da } \\
\text { Silva; VI. Daise Lago Pereira Souto; VII. UNEMAT. }\end{array}$ \\
\hline D.18 & $\begin{array}{l}\text { I. Encontro municipal para educadores de Anápolis em astronomia (emeaa): contribuições } \\
\text { para o ensino de ciências nos anos iniciais; II. 2018; III. Mestrado Profissional; IV. Ensino de } \\
\text { Ciências (52012018007p0); V. Lidia Carla do Nascimento; VI. Cleide Sandra Tavares; VII. UEG. }\end{array}$ \\
\hline D.19 & $\begin{array}{l}\text { I. Abordagem temática e o uso da dinâmica dos três momentos pedagógicos na formação } \\
\text { continuada de professores dos anos iniciais em ciências: contribuições; II. 2018; III. Mestrado } \\
\text { Profissional; IV. Educação em Ciências e Matemática (30004012002p7); V. Jose de Amorim } \\
\text { Theodorio; VI. Maria das Graças Ferreira Lobino; VII. IFES. }\end{array}$ \\
\hline D.20 & $\begin{array}{l}\text { I. Formação continuada de professores dos anos iniciais do ensino fundamental: uma } \\
\text { proposta pautada em sequências de ensino por investigação; II. 2018; III. Mestrado } \\
\text { Profissional; IV. Educação para Ciências e Matemática (52005011002p5); V. Helainy } \\
\text { Waniessy Kenya Rodrigues Silva; VI. Paulo Henrique de Souza; VII. IFG. }\end{array}$ \\
\hline D.21 & $\begin{array}{l}\text { I. Construção de competências e formação continuada de professores do ensino } \\
\text { fundamental em Ilhéus, Bahia a partir do ensino de ciências por investigação; II. 2018; III. } \\
\text { Mestrado Acadêmico; IV. Educação em Ciências (28007018018p3); V. Sueli Fagundes } \\
\text { Moreira; VI. Viviane Briccia do Nascimento; VII. UESC. }\end{array}$ \\
\hline D.22 & $\begin{array}{l}\text { I. A formação do professor/pedagogo e o ensino de ciências nos anos iniciais do ensino } \\
\text { fundamental: estratégias pedagógicas com foco na abordagem sobre microrganismos; II. } \\
\text { 2018; III. Mestrado Profissional; IV. Ensino de Ciências (52012018007p0); V. Wilker } \\
\text { Rodrigues de Oliveira; VI. Solange Xavier dos Santos; VII. UEG. }\end{array}$ \\
\hline
\end{tabular}

Fonte: Autoria própria (2019) - Legenda: Trabalho (I); Ano de realização (II); Tipo de trabalho (III); Programa (IV); Autor (V); Orientador (VI); Instituição de origem (VII).

Após análise do total de 31 trabalhos selecionados, identificou-se que 15 dissertações correspondem às pesquisas realizadas em programas de mestrados profissionais (D.3; D.5; D.6; D.7; D.8; D.9; D.10; D.13; D.14, D.15. D.16; D.18; D.19, D.20; e D.22) e 07 dissertações à pesquisas desenvolvidas em programas de mestrados acadêmicos (D.1; D.2; D.4; D.11; D.12; D.17; e D.21); enquanto todas as 09 teses identificadas, são de programas acadêmicos. Esse é um dado que chama atenção, demonstrando que os mestrados profissionais, mais especificamente os programas de pós-graduação em Ensino de Ciências e Matemática, como um território de considerável interesse pela formação continuada de professores dos anos iniciais e o ensino de Ciências.

Quanto à identificação de trabalhos direcionados para a formação continuada de professores alfabetizadores, apenas 03 dissertações (D.1; D.4; e D.15) demonstraram interesse nesse segmento, com suas investigações sobre alfabetização científica no Ciclo de Alfabetização.

A investigação de Castanheira (2007) (D.1) desenvolveu uma pesquisa etnográfica, um estudo de caso, que teve por objetivo entender como o ensino de Ciências pode ser facilitador do processo de alfabetização nos três primeiros anos do $E F$, a partir de Proximal, de Vigotsky, e das ações de andaimagem, propostas por Bruner e Cadzen, e complementando a noção de pistas de contextualização fornecidas por John Gumperz, dentro de um ambiente construído com a proposta da Pedagogia Culturalmente Sensível (CASTANHEIRA, 2007, Resumo). 
Na sua investigação, Castanheira (2007) demonstrou a possibilidade do ensino de Ciências integrado no aprendizado da leitura e da escrita de crianças de 6 a 8 anos, de uma turma de 2 o ano dos anos iniciais, com ações planejadas com a professora regente, a partir das propostas curriculares, desenvolvendo os temas: os elementos da natureza, ar, água, calor e terra; doenças infectológicas, focando no plano municipal de saúde em tuberculose; e seres vivos animais e vegetais, estudando a metamorfose das borboletas. A pesquisadora caracterizou o movimento CTS como a proposta viável de desenvolvimento desses conteúdos, tendo como perspectiva uma prática reflexiva e crítica dos envolvidos no processo de ensino-aprendizagem, definindo a sala de aula como um ambiente interativo.

Como metodologia para coleta de dados, a autora utilizou entrevista semiestruturada, gravações audiovisuais em VHS e anotações das suas constatações in loco ao longo dos momentos de observação. Realizou a análise por triangulação dos dados, identificando de forma positiva a associação dos fundamentos da Sociolinguística Interacional com a Teoria Vigotskyana de Aprendizagem e a Teoria dos Andaimes de Cadzan, a partir de uma prática pedagógica diversificada com desenvolvimento de conhecimentos das Ciências da Natureza, durante o processo de alfabetização.

O segundo trabalho, trata-se da dissertação de Pereira (2015) (D.4), teve por objetivo entender de que forma as práticas de ensino de Ciências, organizadas pelos professores alfabetizadores, poderiam ser potencializadores dos seus alunos no processo de alfabetização científica, sendo sujeitos da pesquisa, três professoras do Ciclo de Alfabetização, cada uma numa série, diretamente coparticipativas na ações de pesquisa.

O pesquisador se utilizou de observação e filmagem das práticas de ensino das professoras participantes da pesquisa durante o desenvolvimento das suas aulas, e, a partir da análise pelo processo de casos de estudo, identificou a necessidade de maior favorecimento do contato das crianças do Ciclo de Alfabetização com esses conhecimentos, bem como a oferta de propostas de formações continuadas para esses profissional.

No terceiro trabalho identificado, de Diehl (2017) (D.15), o pesquisador desenvolveu uma investigação qualitativa, um estudo de caso, onde analisou como os conteúdos de Física, a partir das sugestões do PNAIC, são inseridos aos alunos do Ciclo de Alfabetização pelos professores alfabetizadores.

Foram sujeitos dessa pesquisa quatro professores alfabetizadores de uma escola pública, e por meio de questionários e entrevistas compartilharam informações da sua formação inicial e continuada, utilizadas como subsídios para o planejamento de uma proposta formativa de $20 \mathrm{~h}$, que aconteceu em dois encontros. No curso, foram desenvolvidos conhecimentos sobre: Espaço: Sol, estrelas, planetas, satélites naturais, satélites artificiais; e Planeta: Terra, ar, água, fogo, animais e vegetais; estados físicos da matéria, calor, temperatura, energia térmica, força, força de atrito, pressão, pressão atmosférica, densidade, empuxo, peso de um corpo, massa de um corpo. Ao final da sua realização, houve a elaboração de uma cartilha de experimentação que auxiliasse os professores alfabetizadores nas aulas de Ciências.

Nas suas conclusões, Diehl (2017) identificou a necessidade de incentivo às práticas experimentais no Ciclo de alfabetização; a oferta nos cursos de Pedagogia 
de disciplinas que valorizem os conhecimentos de física, oportunizando as vivências dos conhecimentos e das práticas experimentais; e de propostas de formação continuada que contemplem, a longo prazo, a educação continuada na área das Ciências da Natureza, para os professores alfabetizadores.

Como constatado, os trabalhos de Castanheira (2007), Pereira (2015) e Diehl (2017) traduzem interesses significativos da educação continuada de professores alfabetizadores, como mediadores dos conhecimentos de Ciências no processo de ensino-aprendizagem da leitura e da escrita, nos três primeiros anos do Ensino Fundamental. Os pesquisadores exploram a prática pedagógica e os saberes docentes instituídos desses professores, valorizando seus contextos e suas vivências formativas, constituinte do perfil profissional docente (NÓVOA, 1995; TARDIF, 2014).

Muitos são os impasses decisórios sobre que proposta mais adequada que deva ser adotada nas práticas para a formação continuada dos professores da educação básica, quando analisamos, principalmente, as questões deterministas de uma postura positivista herdada da própria forma clássica com a qual sempre foi concebida a ciência (ROSA, 2004). Porém, esse é um campo que vem expandindo suas concepções sobre os processos participativos, colaborativos, reflexivos e críticos sobre a prática pedagógica dos professores, fundamentado nos saberes docentes instituídos e próprios do cotidiano pedagógico (MIZUKAMI, et al., 2010; FRANCO; LISITA; 2012; PIMENTA, 2012; TARDIF, 2014), sendo um processo complexo, que deve estar em constante ressignificação epistemológica, na valorização da relação teoria/prática, rompendo com o princípio hegemônico acadêmico de formação docente (COMPIANI, 2015).

\section{CONSIDERAÇÕES FINAIS}

Considerar o ensino de Ciências na infância é fator imprescindível na formação de cidadãos com perfis reflexivos e críticos, dadas às condições típicas da curiosidade humana na Educação Infantil e nos primeiros anos do EF, principalmente, quanto ao processo de apropriação da leitura e da escrita.

Porém, poucos trabalhos ainda são desenvolvidos com interesse na alfabetização científica nos anos iniciais da Educação Básica no Brasil e, principalmente, sobre a formação inicial e continuada dos professores polivalentes, como demonstram os levantamentos mais recentes desenvolvidos sobre o estado de conhecimento desse campo de pesquisa.

Os resultados obtidos nesse trabalho, a partir do Catálogo de Teses e Dissertações da Capes, no período entre os anos de 2007 e 2018, chamam atenção para o aumento e concentração, em âmbito nacional, de pesquisas de mestrado, entre 2014 e 2017, e de doutorado, entre 2014 e 2018, com ênfase nos Programas de Pós-graduação de ensino de Ciências e Matemática, principalmente, de programas de mestrados profissionais.

Sobre a atual situação das investigações brasileiras sobre a educação continuada dos professores alfabetizadores, enquanto mediadores do conhecimento científico, apontados neste trabalho, os resultados nos esclarecem que, do total de 31 trabalhos analisados, que versavam sobre a formação continuada de professores dos anos iniciais, focadas no ensino de Ciências, entre 
teses e dissertações, apenas 03 dissertações se dedicavam a essa temática. Essas pesquisas apresentaram interesse investigativo diversificado, estando direcionadas às práticas pedagógicas de Ciências e como o desenvolvimento dos conhecimentos científicos podem ser potencializador do processo de alfabetização; bem como, com a oferta de propostas formativas experimentais em áreas específicas de Ciências Natureza, como o ensino de Física.

Consideramos que os dados obtidos nesse levantamento contribuem significativamente para a visibilidade da importância de abertura de novas frentes de pesquisa que tratem dessa temática, a formação inicial e continuada de professores alfabetizadores. 


\title{
Science teaching and continuing education of literacy teachers: recognizing the research field
}

\begin{abstract}
Science teaching in the early years of elementary education presents an important research field regarding children's scientific literacy in this segment of education. First, for the typical curiosity of this age range, and later, for the need of building citizen profiles that are reflective and critic to their living environment. However, on the demands for reading and writing appropriation, little attention is given to the construction of Science knowledge, especially in the first three years of elementary education, period of transition between Preschool and Elementary School. In the perspective of the appreciation of Science teaching during literacy, this study aimed to identify and analyze researches, theses, and dissertations that discuss the continuing education of literacy teachers as mediators of scientific knowledge in the Literacy Cycle. For the study, it was used the Catalog of Theses and Dissertations of the Higher Education Personnel Improvement Coordination (Capes), within the delimited period from 2007 to 2018. There have been retrieved 73 works, of which, 31 address the continuing education of teachers of elementary school, focused on Science education, demonstrating an increase in the number of researches that show this interest. But of those, only 03 Master's dissertations were dedicated to the continuing education of literacy teachers, indicating the need for research that may collaborate with new guidance for scientific literacy mediated by the teacher who lectures reading and writing.
\end{abstract}

KEYWORDS: Basic literacy cycle. Literacy. Continuing education. Scientific education. 


\section{AGRADECIMENTOS}

O presente trabalho foi realizado com apoio da coordenação de aperfeiçoamento de pessoal de nível superior - Brasil (Capes) - código de financiamento 001.

\section{REFERÊNCIAS}

AKERSON, V. L. How do Elementary Teachers Compensate for Incomplete Science Content Knowledge?. Research in Science Education. vol. 35, n. 2, p. 245-268, 2005.

ALAVARSE, O. M.; BRAVO, M. H.; MACHADO, C. Avaliações externas e qualidade na educação básica: articulações e tendências. Estudos em Avaliação Educacional, São Paulo, v. 24, n. 54, p. 12-31, jan./abr. 2013. Disponível em: https://www.fcc.org.br/pesquisa/publicacoes/eae/arquivos/1783/1783.pdf. Acesso em: 05 jun. 2019.

AUGUSTO, T. G. da S.; AMARAL, I. A. do. A formação de professoras para o ensino de ciências nas séries iniciais: análise dos efeitos de uma proposta inovadora. Ciênc. educ. (Bauru), Bauru, v. 21, n. 2, p. 493-509, Jun. 2015. Disponível em: http://www.scielo.br/pdf/ciedu/v21n2/1516-7313-ciedu-21-02-0493.pdf. Acesso em: 05 jun. 2019.

BRASIL. Ministério da Educação. Lei no 9.394, de 20 de dezembro de 1996. Estabelece as diretrizes e bases da educação nacional. Diário Oficial da União, Brasília, DF, 23 dez. 1996.

BRASIL. Ministério da Educação. Lei no 11.274, de 6 de fevereiro de 2006. Altera a redação dos arts. 29, 30, 32 e 87 da Lei no 9.394, de 20 de dezembro de 1996, que estabelece as diretrizes e bases para a educação nacional, dispondo sobre a duração de 9 (nove) anos para o ensino fundamental, com matrícula obrigatória a partir dos 6 (seis) anos de idade. Diário Oficial da União, Brasília, DF, 7 fev. 2006.

BRASIL. Ministério da Educação. PORTARIA NORMATIVA №- 10, DE 24 DE ABRIL DE 2007. Institui a Avaliação de Alfabetização "Provinha Brasil", a ser estruturada pelo Instituto Nacional de Estudos e Pesquisas Educacionais "Anísio Teixeira"INEP. Diário Oficial da União, Brasília, DF, 10 de abr. 2007.

BRASIL. Ministério da Educação. PORTARIA № 867, DE 4 DE JULHO DE 2012. Institui o Pacto Nacional pela Alfabetização na Idade Certa e as ações do Pacto e define suas diretrizes gerais. Diário Oficial da União, Brasília, DF, 4 jul. 2012.

BONAMINO, A.; SOUSA, S. Z. Três gerações de avaliação de educação básica no Brasil: interfaces com o currículo da/na escola. Educação e Pesquisa, São Paulo, v. 38, n. 2, p. 373-388, abr./jun. 2012. Disponível em:

http://www.scielo.br/pdf/ep/v38n2/aopep633.pdf. Acesso em: 05 jun. 2019.

CAPES - Coordenação de Aperfeiçoamento de Pessoal De Nível Superior. 10 perguntas e respostas para facilitar a rotina acadêmica. Boletim Eletrônico: 
http://mailer.periodicos.capes.gov.br//?m=74\&p=view\&pi=ViewBrowserPlugin\& uid=f282a2a8d9a3bd80e2da70baff08b48c. Acesso em: 06 mar. 2019.

CAPES - Coordenação de Aperfeiçoamento de Pessoal De Nível Superior. OPÇÃO "buscar assunto" permite aplicação de estratégias de pesquisa. Boletim Eletrônico: CAPES Periódicos, Brasília, DF, n. 52, p.1-1, 31 out. 2018. Disponível em:

http://mailer.periodicos.capes.gov.br//?m=92\&p=view\&pi=ViewBrowserPlugin\& uid=f282a2a8d9a3bd80e2da70baff08b48c. Acesso em: 06 mar. 2019.

CASTANHEIRA, S. F. Estudo etnográfico das contribuições da sociolingüística à introdução ao letramento científico no início da escolarização. 2007. Dissertação (Mestrado em Educação) - Faculdade de Educação, Universidade de Brasília, Brasília, 2015.

CHASSOT, A. Alfabetização científica: questões e desafios para a educação. 6 ed. Ijuí: Unijuí, 2014.

COMPIANI, M. Aprofundando a concepção de pedagogia crítica do lugar/ambiente. In. (Org.) Ribeirão Anhumas na escola: pesquisa colaborativa entre escola e universidade gerando conhecimentos contextualizados e interdisciplinares. Curitiba: Editora CRV, 2015.

DIEHL, C. R. P. da S. Práticas experimentais em física: uma abordagem para os anos iniciais do ensino fundamental. Dissertação (Mestrado) - Instituto Federal Sul-Rio-Grandense, Campus Pelotas Visconde da Graça, Programa de Pós Graduação em Ciências e Tecnologias na Educação, 2017.

DIXON, P.; WILKE, R. A. The Influence of a Teacher Research Experience on Elementary Teachers' Thinking and Instruction. Journal of Elementary Science Education. Peoria: Western Illinois Université, vol. 19, n. 1, p. 25-43, 2007.

FERNANDES, R. C. A. Inovações pedagógicas no ensino de ciências dos anos iniciais: um estudo a partir de pesquisas acadêmicas brasileiras (1972-2012). 2015. Tese (Doutorado em Educação) - Faculdade de Educação, Universidade Estadual de Campinas, Campinas, 2015.

FONSECA, M. R. L. M. Alfabetização, letramento e numeramento: conceitos como processo discursivo. In. (Org.) GOULART, M. A.; GONTIJO, C. M.; FERREIRA, N. S. F. A alfabetização como processo discursivo: $\mathbf{3 0}$ anos de $A$ criança na fase inicial da escrita. São Paulo: Cortez, 2007.

FRACALANZA, H.; AMARAL, I. A.; GOUVEI, M. S. F. O ensino de ciências no primeiro grau. v. 1, São Paulo: Atual, 1986.

FRANCO, M. A. S.; LISITA, V. M. S. de S. Pesquisa-ação: limites na formação docente. In. PIMENTA, S. G.; FRANCO, M. A. S. (Orgs.). Pesquisa em educação: Possibilidades investigativas/formativas da pesquisa-ação. Vol. 2. São Paulo: Loyola, 2008. São Paulo: Edições Loyola, 2012. 
FREIRE, P. Alfabetização: leitura do mundo leitura da palavra. Rio de Janeiro: Paz e Terra, 1990.

FREIRE, P. A importância do ato de ler em três artigos que se completam. 23 ed. São Paulo: Cortez, 1989.

GATTI, B. A. Formação continuada de professores: a questão psicossocial. Cadernos de Pesquisa, São Paulo, n. 119, p. 191-204, jul. 2003. Disponível em: http://www.scielo.br/pdf/cp/n119/n119a10.pdf. Acesso em: 06 mar. 2019.

GOULART, C. M. A. Para conceber o processo de alfabetização na relação com o trabalho da educação infantil: questões culturais, políticas e pedagógicas. In. (Org.) MACEDO, M. S. A. N.; GONTIJO, C. M. M. Políticas e práticas de alfabetização. V. 01; Recife: Editora UFPE, 2017.

IBGE - INSTITUTO BRASILEIRO DE GEOGRAFIA E ESTATÍSTICA. Pesquisa Nacional por Amostra de Domicílios: educação 2019. Rio de Janeiro, 2019. Disponível em: https://biblioteca.ibge.gov.br/visualizacao/livros/liv101657_informativo.pdf. Acesso em: 26 jun. 2019.

INEP - Instituto Nacional de Estudos e Pesquisas Educacionais Anísio Teixeira. Saeb: Sistema de Avaliação da Educação Básica. Brasília, DF, p. 1-1, 03 maio, 2019. Disponível em: http://portal.inep.gov.br/educacao-basica/saeb. Acesso em: 30 jun. 2019.

JARVIS, T.; PELL, A. Primary teachers changing attitudes and cognition during a two-year science in-service programme and their effect on pupils. International Journal of Science Education. London: Routledge, vol. 26, n. 14, p. 1787-1811, 2004.

KUSIAK, S. M. Uma análise da prova Brasil com enfoque nos processos de leitura e escrita. IX ANPED SUL - Seminário de Pesquisa em Educação da Região Sul. 2012. Disponível em:

http://www.ucs.br/etc/conferencias/index.php/anpedsul/9anpedsul/paper/view /265/106. Acesso em: 10 jun. 2019.

LEAL, T. F. Políticas de alfabetização e currículo. In. (org.) MACEDO, M. S. A. N.; GONTIJO, C. M. M. Políticas e práticas de alfabetização. Recife: Ed. EFPE, 2017.

LEITE, S. A. da S. Alfabetização: em defesa da sistematização do trabalho pedagógico. In. ARANTES, V. A. (Org.). Alfabetização e letramento: pontos e contrapontos. 2 Ed. São Paulo: Summus, 2010.

LIMA, L. R. F. de C.; BELLO, M. de O R. B.; SIQUEIRA, M. R. da P. A Formação de Professores das Séries Iniciais e sua Relação com o Ensino e Aprendizagem: Uma Revisão em Periódicos Brasileiros. Revista Brasileira de Ensino de Ciência e Tecnologia. v. 8. ed. Sinect, jan-abr. 2015. Disponível em: https://periodicos.utfpr.edu.br/rbect/article/view/2955. Acesso em: 10 jan. 2019. 
LONGHINI, M. D. O conhecimento do conteúdo científico e a formação do professor das séries iniciais do ensino. Investigações em Ensino de Ciências. Porto Alegre: Universidade federal do Rio Grande do Sul, vol. 13, n. 2, p. 241-253, 2008.

LONGHINI, M. D.; HARTWIG D. R. A interação entre os conhecimentos de um professor atuante e de um aspirante como subsídio para a aprendizagem da docência. Ciência \& Educação. Bauru: Faculdade de Ciências - Unesp, vol. 13, n. 3, p. 435-451, 2007.

LORENZETTI, L.; DELIZOICOV, D. Alfabetização científica no contexto das séries inicias. Ensaio - Pesquisa em Educação em Ciências, v. 3, n. 1, jun. 2001. Disponível em: http://www.scielo.br/pdf/epec/v3n1/1983-2117-epec-3-0100045.pdf. Acesso em: 10 jan. 2019.

MAGALHÃES JÚNIOR, C. A. O.; TOMANIK, E. A. Representações sociais de meio ambiente: subsídios para a formação continuada de professores. Ciência \& Educação, v. 19, n. 1, p. 181-199, 2013. Disponível em: http://www.scielo.br/scielo.php?script=sci_abstract\&pid=S1516$73132013000100013 \&$ Ing=en\&nrm=iso\&tlng=pt. Acesso em: 15 mar. 2019.

MARCíLIO, M. L. História da alfabetização no Brasil. São Paulo: Editora da Universidade de São Paulo, 2016.

MEGID NETO, J.; ROCHA, M. B. Práticas de formação de professores para o ensino de ciências nos anos iniciais do ensino fundamental: uma revisão da literatura. Ensino Em-Revista, Uberlândia, v. 17, n. 1, p. 155-176, jan./jun.2010. Disponível em: http://www.seer.ufu.br/index.php/emrevista/article/view/8189. Acesso em: 10 mar. 2019.

MIZUKAMI, M. da G. N. et al. Escola e aprendizagem da docência: processos de investigação e formação. São Carlos: EdUFSCar, 2010.

MONTEIRO, M. A. A.; TEIXEIRA O. P. B. O ensino de Física nas séries iniciais do Ensino Fundamental: um estudo das in fluências das experiências docentes em sua prática em sala de aula. Investigações em Ensino de Ciências. Porto Alegre: Universidade do Rio Grande do Sul, vol. 9, n. 1, 2004. Disponível em: https://www.if.ufrgs.br/cref/ojs/index.php/ienci/article/view/535/330. Acesso em: 10 jun. 2019.

MORORÓ, L. P.; BASSO, I. S. A influência da formação continuada: elementos mediadores necessários à ruptura das formas de pensamento cotidiano do professor sobre a prática pedagógica. In. Processos formativos da docência: conteúdos e práticas. (Org.) MIZUKAMI, M. DA G. N.; REALI, A. M. DE M. R. São Carlos: EdUFSCar, 2005.

NARDI, Roberto. A pesquisa em ensino de Ciências e Matemática no Brasil. Ciênc. educ. (Bauru), Bauru, v. 21, n. 2, p. I-V, jun. 2015. 
NILSSON, P. Teaching for understanding: The complex nature of pedagogical content knowledge in pre-service education. International Journal of Science Education, London: Routledge, vol. 30, n. 10, p. 1281-1299, 2008.

NÓVOA, A. Os professores e a sua formação. 2 ed., Lisboa: Publicações Dom Quixote, 1995.

PEREIRA, I. D. M. Ensino de ciências na perspectiva da alfabetização científica: prática pedagógica no ciclo de alfabetização. 2015. Dissertação (Mestrado) Programa de Pós-graduação em Educação - Faculdade de Educação, Universidade Federal de Pelotas, 2015.

PIMENTA, S. G. Formação de professores: identidade e saberes da docência. In. PIMENTA, S. G. (Org.). Saberes pedagógicos e atividades docente. 8 ed., São Paulo: Cortez, 2012.

ROSA, M. I. P. Investigação e ensino: articulações e possibilidades na formação de professores de ciências. Ijuí: Ed. Unijuí, 2004.

SAÇKES, M.; FLEVARES, L. M.; TRUNDLE, K. Four- to six-year-old cildren's conceptions of the mechanism of rainfall. Early Childhood Research Quarterly, 25, 2010. (p. 536-546). Disponível em:

https://www.researchgate.net/publication/248544412_Four_to_six-yearold_children's_conceptions_of_the_mechanism_of_rainfall. Acesso em: jan. 2019.

SAVIANI, D. Escola e democracia. Campinas, SP: Autores Associados, 2008.

SILVA, A. V. P. A construção do saber docente no ensino de ciências para as séries iniciais. In: NARDI, R. (Org.). Questões atuais no ensino de ciências. São Paulo: Escrituras, 2009. p. 33-41.

TARDIF, M. Saberes docentes e formação profissional. Petrópolis, RJ: Vozes, 2014.

TRUNDLE, K. C. Teaching science during the early childhood years. National Geographic Science, 2009. Disponível em:

http://ngspscience.com/profdev/Monographs/SCL22-

0429A_SCl_AM_Trundle_lores.pdf. Acesso em: 10 jan. 2019.

TRUNDLE, K. C.; ATWOOD, R. K.; CHRISTOPHER, J. E. Preservice elementary teachers' knowledge of observable moon phases and pattern of change in phases. Journal of Science Teacher Education. Pittsburgh, vol. 17, n. 2, p. 87-101, 2006.

VIECHENESKI, J. P.; LORENZETTI, L. CARLETTO, M. R. A alfabetização científica nos anos iniciais: uma análise dos trabalhos apresentados nos ENPECs. X ENPEC, Águas de Lindóia, SP, nov. 2015. Disponível em:

http://www.abrapecnet.org.br/enpec/x-enpec/anais2015/resumos/R0409-1.PDF. Acesso em: 10 jan. 2019. 
VIEIRA, R. V.; TENREIRO-VIEIRA, C.; MARTINS, I. P. A educação em ciências com orientação cts: atividades para o ensino básico. Porto: Areal Editores, 2011.

ZIMMERMANN, E.; EVANGELISTA P. C. Q. Pedagogos e o ensino de física nas séries iniciais do ensino fundamental. Caderno Brasileiro de Ensino de Física. Vol. 24, n. 2, p. 261-280.Florianópolis: UFSC, 2007.

Recebido: 12 ago. 2019

Aprovado: 28 out. 2019

DOI: $10.3895 /$ actio.v4n3.10507

Como citar:

GONÇALVES, E. N. C.; COMPIANI, M.; JÚNIOR MAGALHÃES, C. A. O. O ensino de ciências e a formação continuada de professores alfabetizadores: reconhecendo o campo de pesquisa. ACTIO, Curitiba, v. 4, n. 3 ,

p. 270-291, set./dez. 2019. Disponível em: <https://periodicos.utfpr.edu.br/actio>. Acesso em: XXX

Correspondência:

Emerson Nunes da Costa Gonçalves

Cidade Universitária "Zeferino Vaz", Campinas, SP, Brasil CEP 13.083-970.

Direito autoral: Este artigo está licenciado sob os termos da Licença Creative Commons-Atribuição 4.0

Internacional.

(c) (i) 